\title{
Research Paper: The Effect of a Six-week Core Stability Exercises on Balance, Strength, and En- durance in Female Students With Trunk Defects
}

\author{
Zahra Mohebi Rad ${ }^{1}$ (D), Ali Asghar Norasteh ${ }^{1}$ (i)
}

1. Department of Corrective Exercises and Sport Injuries, Faculty of Physical Education and Sport Sciences, University of Guilan, Rasht, Iran.

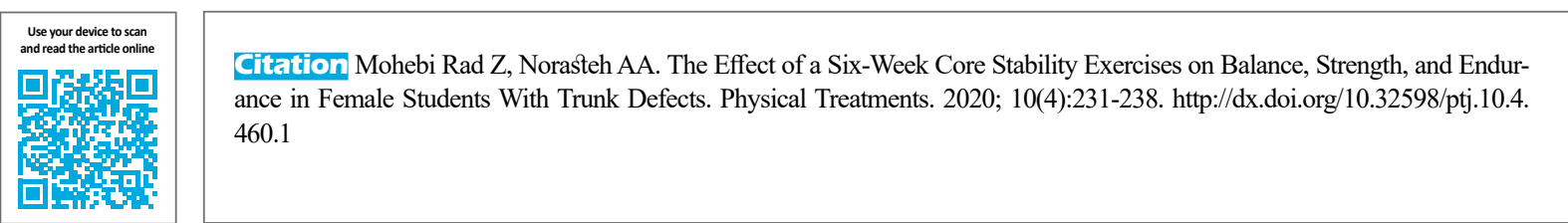

\section{(i) (3)}

Article info:

Received: 15 May 2020

Accepted: 12 Aug 2020

Available Online: 01 Oct 2020

Keywords:

Core stability exercises, Balance, Student, Trunk defects $\vdots$

\section{A B S T RA C T}

Purpose: Core stability is the ability of the lumbopelvic-hip complex to prevent spinal instability and return to equilibrium after a perturbation. The special physical condition in students and especially the female ones-makes them prone to Trunk Defects (TDs); thus, it makes them prone to numerous injuries, like problems in balance. The present study aimed to examine the effect of Core Stability Exercises (CSEs) on static and dynamic balance, strength, and endurance among female students with TDs.

Methods: This was a quasi-experimental study with a pretest-posttest design. The study samples were 30 female high-school students with TDs (Mean \pm SD age: $15.63 \pm 0.49$ y, height: $1.60 \pm 0.04$ $\mathrm{m}, \&$ weight: $55.96 \pm 6.08 \mathrm{~kg}$ ). All the subjects were placed in the same group. The Star Excursion Balance Test (SEBT) was used to evaluate the dynamic balance; One-Legged Stance Test (OLST) was employed to evaluate the static balance; the McGill test was applied to evaluate trunk endurance; a dynamometer was used to assess the trunk muscle strength, and tuck-jump screening test was implemented to determine students with TDs. These tests were employed at pretest and posttest phases. The research subjects followed CSEs for 6 weeks, 3 sessions per week, and approximately 45 minutes per session, supervised by the researcher. The Dependent Samples t-test at the significance level of $\mathrm{P}=0.05$ was used for data analysis.

Results: The present study results indicated a significant difference in strength, muscular endurance, as well as static and dynamic balance in the study subjects after the exercise program $(\mathrm{P}=0.001)$.

Conclusion: According to the data, 6 weeks of CSEs could provide a solid foundation for the transfer of forces between the limbs. This is achieved by enhancing the strength and endurance of the core muscles of the body; accordingly, it leads to improved static and dynamic balance in female students with trunk control defect by reducing postural fluctuations. However, further extensive studies with larger sample sizes are required for providing more accurate conclusions.

\section{* Corresponding Author:}

Zahra mohebi rad. Msc.

Address: Department of Sport Injuries and Corrective Exercise, Faculty of Physical Education and Sport Sciences, University of Guilan, Rasht, Iran.

Phone: +98 (936) 5606023

E-mail: zahra.mr2012@yahoo.com 


\section{Highlights}

- Trunk defects in adolescents and students can cause back pain in adulthood and lead to great socio-economic damage to society.

- Trunk defect is simply defined as the inability to precisely control the trunk in three dimensions. Deficiency in the neuromuscular control of trunk movements and delayed muscle response predispose to back and lower limb injuries.

- Core stability exercises include a wide range of exercises that aim to improve the control of the lumbopelvic and abdominal muscles. This is achieved by improving the strength and endurance of the core muscles. These exercises also lead to improved static and dynamic balance; all of which reduce the risk of injury.

\section{Plain Language Summary}

Core stability exercises improve the stability of the central region of the body and increase the strength and endurance of the core muscles. Besides, they improve static and dynamic balance in students; accordingly, the strategy of calling the muscles of this region is improved. Ultimately, this process reduces the risk of injuries to the trunk and lower limbs. The present study results revealed that core stability exercises lead to significant differences in strength, core muscle endurance, and static and dynamic balance in individuals.

\section{Introduction}

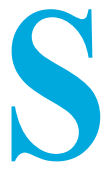

tudents spend $30 \%$ of the day at school, might be in a sitting position with bent back, torso, and neck [1]. Overall, most students' daily time is spent sitting for studying, working with computers, and daily living activities. Besides, the body posture is affected by long sitting positions, as well as carrying heavy backpacks by the students. Over time, the musculoskeletal body system adapts to this state; subsequently, a negative consequence is the weakness of the core muscles of the body $[2,3]$. The muscles of the body center are responsible for distributing load and pressure. When the activation of these muscles is delayed, the pressure on other parts of the body increases; accordingly, the odds of the disruption of healthy movement patterns increases, leading to multiple injuries. Exercises lead to excessive loads on the lower limbs in both genders; however, these movements cause greater injuries in women [4].

In this regard, three main reasons for the susceptibility of women to lower extremity injuries and anterior cruciate ligament injuries have been mentioned; anatomical, hormonal, and neuromuscular characteristics [5]. The studies on the effect of neuromuscular factors on women's injury indicated that females have defects in the neuromuscular control system, compared to males [6]. Neuromuscular defects have been defined as inappropriate patterns of activation, low muscle strength, and power [5]. A defect of neuromuscular control is the lack of control of the trunk (trunk dominance) or the dysfunction of the body core [7]. Core dysfunction is simply defined as the inability to control the trunk in three dimensions precisely [8].

Thus, defect in the neuromuscular control of the central part of the body leads to increased uncontrolled movement of the trunk $[4,5]$. The lack of neuromuscular control of trunk movements and delayed muscle response during exercise predispose the individual to lower back, as well as lower limb injuries; these conditions reveal the existing risk factors in the individual [9]. Trunk control defect has also been defined as inadequate coordination and control to resist trunk inertia during landing. During landing movements, the rotation and reduction of torso movement acceleration in those with this defect are much higher and angular; thus, the torso movement is more affected by the produced inertia and the function of the muscles of the central region play a limited role in controlling the torso $[8,10]$.

Improper control in the central part and the defect in the ability to disperse forces lead to excessive torso movements, especially in the transverse plane [10]. The literature reflects that central stability is an essential component of any motor activity. Most evidence supports the integrity of the relationship between core stability and musculoskeletal damage. An unstable or weak core can lead to organ damage and poor balance during function [11]. Balance is a complex motor skill that describes the 
dynamics of the body in preventing falls [12]. Maintaining balance in a static state or during activity necessitates the generation of sufficient muscle strength, requiring a complex interaction of the neuromuscular system [13].

Sedaghati et al. examined the effects of 8 weeks of Core Stability Exercises (CSEs) on the athletic performance of adolescent swimmers. They explored the subjects in terms of the endurance and strength of trunk muscles, dynamic balance, and swimming speed; all of which indicated significant improvement at the end of the exercises [14]. Sandri et al. evaluated the effect of 6 weeks of CSEs on dynamic balance and core muscle endurance in highschool athletics athletes. At the end of the 6 weeks, the collected results indicated a significant improvement in core muscle endurance and balance [15]. Imai et al. investigated the effects of two types of trunk exercises, including stability exercises and traditional trunk exercises on static and dynamic balance, and the athletic performance of young football players. At the end of the 12 weeks of the training program, trunk stability exercises resulted in further improvement in static and dynamic balance and athletic performance of the explored subjects [16].

Nasr et al. studied the relationship between core stability and core muscle strength, and the performance of female soccer players; they observed no relationship between core stability and muscle strength, and the performance of female soccer players [17]. Seok Kim et al. assessed the effect of 12-week CSEs on low back pain, static balance, and trunk muscle strength among older women. At the end of the 12 weeks, the rate of a back disability and trunk muscle strength improved; however, no improvement was detected in the static balance of the explored samples [18]. CSEs include a wide range of exercises that attempt to enhance pelvic lumbar and abdominal muscle control, and subsequently improve balance. These exercises are designed to enhance the ability of the musculoskeletal and motor control systems to prevent injuries to the spine, as well as the lower limbs [19].

Although numerous scholars have supported the effectiveness of CSEs in improving Trunk Defects (TDs), and the level of balance, strength, and endurance of the core muscles, there are few conflicting studies. Furthermore, it seems that similar studies on adolescents and students are scarce. As most adolescents are engaged in education, exploring the students seems necessary. In school, three main factors predispose students to injury, including heavy backpacks ( $>10 \%$ of body weight), an improper design of teaching aids and equipment, and incorrect sitting postures that lead to poor posture among the students in the long-run. Moreover, there will be

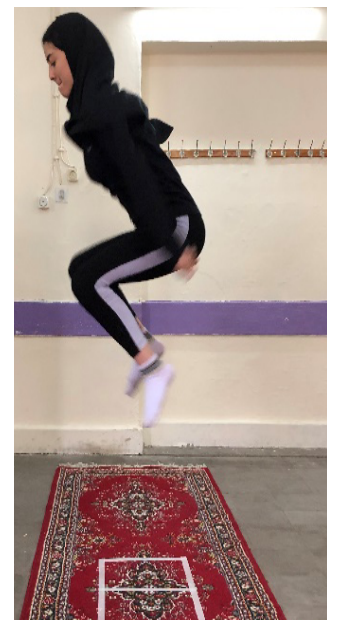

Figure 1. Tuck jump test

PHYSICAL TREA $\$ MENTS

damage and weakness of the core muscles of the body and a decrease in balance. Additionally, conducting studies and taking preventive measures seem necessary. This is because of the sensitivity of adolescence, especially the girls, given the type of clothing and the sensitivity of the issue in promoting community health.

\section{Materials and Methods}

This was a quasi-experimental study with a pretest and posttest design. The study population was $30 \mathrm{fe}-$ male high-school students in the tenth grade with TDs. The study subjects were selected using the convenience purposive sampling method from the Tohid Girls' HighSchool in Lahijan City, Iran. The inclusion criterion was being high-school girls with TDs, interested in participating in the study. The tuck jump test (Figure 1) was used to determine TDs in the study participants. The exclusion criteria were a history of professional exercise, surgery, and serious injuries to the spine and lower extremities, back pain, spinal abnormalities, and visible misalignments in the lower extremities. The tuck jump test was applied to select the subjects by screening tenthgrade students. Tuck jump with $67 \%$ specificity, and $84 \%$ sensitivity is used to identify the individuals with trunk neuromuscular control deficiency [20].

Herrington et al. (2013) reported the intergroup and intragroup validity of the tuck jump test as very good to excellent [21]. The student stands with his/her legs shoulder-width apart and begins to jump vertically, raising the knees as high as possible to perform the tuck jump. While landing, the student must start the next tuck jump. The test was conducted for 10 seconds. Prior to performing the test, all of its steps were explained to the subjects in detail. Two video cameras (front $\&$ side 
views) were implemented to enhance the evaluation accuracy. Kinova software was used to check the jump sequences after conducting the test. According to the rules of this test, those with 3 characteristics at the same time during the tuck jump are recognized as those with TDs; pausing during jumps, not having thighs parallel to the ground at the peak of their jumps, and not landing on their starting footsteps [21]. After screening the students, pretests related to balance, strength, and endurance were conducted, and the relevant posttests were recorded at the end of the training sessions. Fifty-seven students participated in the screening; of whom, 32 had TDs, and two were excluded from the study because of failure to complete the training sessions.

Static balance: The study subjects were evaluated for static balance through the One-legged Stance Test (OLST). The subjects stood on a flat floor with their weight on the soles of their feet, their upper limbs away from their bodies, and their eyes closed. After the start command was issued, the subjects raised their non-dominant hip joint and bent 90 degrees, the examiner turned on the stopwatch, and the evaluation was completed when the subject opened his eyes or touched the ground. The unit of measurement was in seconds [22].

Dynamic balance: SEBT was used to evaluate the dynamic balance in the study subjects. Initially, 8 lines were determined on the ground with a distance of 45 degrees from each other. The subjects stood with their nondominant legs in the center of these lines and their hands resting on their hips. The subject was requested to touch the farthest possible point on the lines with her dominant toe and hit the ground, slightly. The subject performed the test 3 times for each direction and her maximum record was recorded in centimeters. If the subject failed to stand on one foot; lift, or move the support leg, or encountered difficulty returning the dominant leg to the center point; upset his or her balance, and placed the foot before the center point of the ground; she discontinued the test, and repeated it as before. The records related to dynamic balance were divided by the length of the subjects' legs and reported in percentage $[16,23]$.

Muscular endurance: The valid McGill test was employed to evaluate the stability of the core trunk area, including sitting at a 60-degree angle (the endurance of trunk flexors), Sorensen test (the endurance of trunk extensions), as well as Planck and Planck on both sides (the endurance of lateral trunk muscles) [24].

Muscular strength: The isometric strength of selected muscles (flexor \& trunk extensor, \& lateral trunk flexors) was measured and recorded using a hand dynamometer (MMT. North coast, USA). All test positions were selected based on the positions expressed in the texts and as anti-gravity. Prior to performing the test, the subject was explained to conduct it and was allowed to perform the test once, as a practice. Each test was measured three times. Each time, the isometric contraction was measured for 5 seconds; a break of 15 seconds was considered between each contraction, and the maximum force was recorded and used in the final analysis. In the final analysis, the measured values for muscle strength were evaluated separately (flexor, extensor, \& lateral flexor) and as a sum of trunk strength (mean flexor, extensor, \& lateral flexor muscles) $[25,26]$.

CSEs used in the study were adopted from the 12-week CDEs of young football players that Imai et al. (2014) used in their study [16]. The reason for selecting this exercise program was the simplicity and appropriateness of the initial exercises and the gradual process of increasing the intensity of these exercises. In this study, the research subjects followed the CSEs for 6 weeks and three 45-minute sessions per week under the supervision of the researcher. Before the exercises, warm-up practices were performed for 10 minutes; at the end, cool-down exercises were performed for 5 minutes. The intensity of the exercises increased based on the examiner's evaluation and gradually based on the students' tolerance. This protocol involved 8 movements, including front plank; quadruped exercise; back plank; side bridge; sit-ups; alternating situp; back extension, and alternating superman.

The rest time between repetitions and exercises was 5 seconds and 2 minutes, respectively. At the end of the 6 weeks, balance, strength, and endurance tests were reperformed. Eventually, after collecting the research information, data related to the characteristics of the subjects, such as age, height, and weight, as well as research variables concerning descriptive and inferential statistics were analyzed in SPSS. Shapiro-Wilk test was used to evaluate the normality of data distribution, and Dependent Samples t-test was employed to compare the mean pretest and posttest values of strength, muscle endurance, as well as the static and dynamic balance of the subjects at a significance level of $95 \%$ with $\mathrm{P} \leq 0.05$. The ethical code of the present study was IR.GUMS. REC.1397.503.

\section{Results}

Shapiro-Wilk test data indicated the normal distribution of data in all contextual variables in the study groups 
Table 1. Demographic characteristics of the research subjects

\begin{tabular}{cc}
\hline Variables & Mean \pm SD \\
\hline Height $(\mathrm{m})$ & $1.60 \pm 0.04$ \\
\hline Weight $(\mathrm{kg})$ & $55.96 \pm 6.08$ \\
Age $(\mathrm{Y})$ & $15.63 \pm 0.49$ \\
${ }^{*} \mathrm{BMI}\left(\mathrm{kg} / \mathrm{m}^{2}\right)$ & $21.62 \pm 1.36$ \\
\hline
\end{tabular}

*BMI: Body Mass Index.

PHYSICAL TREATMENTS

Table 2. The difference between the pretest-posttest mean scores of strength, muscle endurance, and static and dynamic balance in the study subjects

\begin{tabular}{|c|c|c|c|c|}
\hline \multirow{2}{*}{ Variables } & \multicolumn{2}{|c|}{ Mean $\pm S D$} & \multirow{2}{*}{$\mathbf{t}$} & \multirow{2}{*}{$\mathbf{P}$} \\
\hline & Pretest & Posttest & & \\
\hline Muscle strength & $10.33 \pm 0.26$ & $11.52 \pm 0.49$ & -18.07 & $0.001^{*}$ \\
\hline Muscle endurance & $32.46 \pm 12.14$ & 52.1217 .83 & -8.91 & $0.001 *$ \\
\hline Static balance & $15.44 \pm 10.11$ & $25.30 \pm 13.45$ & -4.58 & $0.001^{*}$ \\
\hline Dynamic balance & $74.17 \pm 9.41$ & $80.85 \pm 8.30$ & -7.84 & $0.001 *$ \\
\hline
\end{tabular}

* Significant level at $\mathrm{P}<0.01$.

PHYSICAL TREA MENTS

$(\mathrm{P}<0.05)$. The demographic characteristics of the studied subjects are listed in Table 1.

The Dependent Samples t-test was used to evaluate the differences between the pretest and posttest scores in the training group; the related results suggested significant differences in strength, muscle endurance, and static and dynamic balance $(\mathrm{P}<0.001)$ (Table 2$)$.

\section{Discussion}

The current study examined the effect of a six-week CSEs on the static and dynamic balance among highschool female students with TDs. The obtained results indicated that the provided training significantly impacted the strength, muscle endurance, and static and dynamic balance of the study subjects. Seok Kim et al. investigated the effect of a 12-week core stability training on low back pain, static balance, and trunk muscle strength in old women. At the end of the exercise sessions, the degree of a back disability, back pain, and trunk muscle strength improved; however, no improvement was observed in the static balance of the samples [18].

A reason for the inconsistency of their results with those of the present study is that static balance depends on characteristics, such as proprioception, muscle activation patterns, visual feedback, and the vestibular system. As the intervention program of the study focused on improving proprioception and trunk muscle strength without affecting the vestibular system and vision, the static balance remained unimproved. Nasr et al. (2009) explored the relationship between core stability and muscle strength, and athletic performance indices in female soccer players; their data were not in line with those of ours. They documented no correlation between these factors. Besides, the potential reason for these results was that the tests used in this study to measure core strength were not specific.

Imai et al. (2014) argued that 12 weeks of trunk stability training enhances static and dynamic balance and the athletic performance of young football players [16]. Sedaghati et al. (2018) explored intensive 8-week CSEs and their effect on the strength, endurance, balance, and athletic performance of adolescent competitive swimmers. The relevant results revealed significant differences in flexor and extensor muscle endurance; core muscle strength; dynamic balance, and swimming speed before and after exercise [14]. The difference between this study and the present one was that their study subjects were professional swimmers, but not the present study participants.

Razavi et al. (2014) studied the relationship between core stability and static and dynamic balance in male snowboard athletes. The collected results presented a 
significant relationship between core endurance, core strength, and lumbar-pelvic complex function, and static balance. Nevertheless, there were no significant relationships between core power and static balance. Besides, there was a significant association between endurance, strength, central strength, and lumbar-pelvic complex, and dynamic balance [27]. Sandri et al. (2013) examined the effect of 6 weeks of CSEs on dynamic balance and core muscle endurance in high-school athletes in athletics. At the end of the 6 weeks, the results of evaluations reflected a significant improvement in core muscle endurance and balance [15]. Liang et al. (2016) studied the effect of CSEs on the dynamic balance of healthy students. The related results signified that students' dynamic balance improved after 6 weeks of CSEs [28]. Kohl and Gribel (2009) stated that dynamic balance improved after 6 weeks of CSEs in the training group, compared to the controls [29]. The results of these studies are in line with those of the present study.

The stability of the body core region is essential to create the right balance against the forces applied to the spine, pelvis, and motor chains, and to initiate the functional movements of the limbs. The proper function of the core muscles (by the proper distribution of force in the lumbarpelvic region \& preventing excessive pressure \& compensatory pelvic movements along with the limbs) improves the function of the musculoskeletal system throughout the motor chain; ultimately, this process provides better static and dynamic balance during activity [11].

Balance is a key and integral component in daily living activities and sports functions. Performing and maintaining balance in a static and dynamic position requires the generation of sufficient force by the muscles and its application to the body levers; it requires a complex interaction between the musculoskeletal and the nervous systems [23]. Proper balance is strongly correlated with muscle strength in different areas of the body, especially in the core. This is because the strength of the muscles in the core that connect the limbs is an essential component of control and balance. The strength of the muscles in the joints of the spine indicates that this part of the body does not depend or has little dependence on passive stability. Muscle strength in joints or other organs also causes balance; however, not as much as the muscles in the core.

This is because stability in the core first creates the connection of the limbs; then increases the performance of the limbs during various movements that need to control and engage the upper and lower limbs together. These studies highlight that by improving the strength and endurance of the core muscles of the body, CSEs provide a solid foundation for the transfer of forces between the limbs; thus, it optimally activates the systems involved in balance control, leading to an improvement in static and dynamic balance by reducing postural fluctuations.

More precisely, CSEs improve static and dynamic balance in two ways, as follows: firstly, by increasing the strength and empowerment of the abdominal muscles, which stabilize the body core for lower limb movements. Accordingly, such stabilization leads to fewer trunk oscillations and greater balance. Secondly, CSEs lead to the proper training of the neuromuscular control system, where the core muscles are called at the right time to take responsibility for preventing imbalance during turbulence. Among the limitations of the study was the lack of a control group. Moreover, as the samples were all students, and the study was conducted in the school environment, we sometimes had trouble coordinating time with teachers for students' exercise time.

\section{Conclusion}

Given the results of the present study and those of the previous studies, CSEs can improve static and dynamic balance in female students with TDs. Based on the data, it is recommended that these exercises be used to prevent injuries to the trunk and lower limbs in students and during their physical education hours.

\section{Ethical Considerations}

\section{Compliance with ethical guidelines}

This study was approved by the Ethics Committee of the Guilan Medical Sciences University (Code: IR.GUMS.REC.1397.503).

\section{Funding}

This research received no specific grant from funding agencies in the public, commercial, or non-profit sectors

\section{Authors' contributions}

All authors equally contributed to the present study.

\section{Conflict of interest}

The authors declared no conflicts of interest.

\section{Acknowledgments}

The authors would like to thank the Vice-Chancellor for Research of Guilan University, Department of Edu- 
cation, Tohid Girls' High School in Lahijan, and all studied students for their sincere cooperation.

\section{References}

[1] Nurul Asyikin MA, Shamsul BM, Mohd Shahrizal D, Mohamad Azhar MN, Mohd Rafee B, Zailina H. Neck, shoulder, upper and lower back pain and associated risk factors among primary school children in Malaysia. Journal of Medical Safety. 2009; 2:37-47.

[2] Bygrave S, Legg SJ, Myers S, Llewellyn M. Effect of backpack fit on lung function. Ergonomics. 2004; 47(3):324-9. [DOI:10. 1080/0014013031000157869] [PMID]

[3] Syazwan AI, Azhar MM, Anita AR, Azizan HS, Shaharuddin MS, Hanafiah JM, et al. Poor sitting posture and a heavy schoolbag as contributors to musculoskeletal pain in children: An ergonomic school education intervention program. Journal of Pain Research. 2011; 4:287-96. [DOI:10.2147/JPR. S22281] [PMID] [PMCID]

[4] Myer GD, Brent JL, Ford KR, Hewett TE. Real-time assessment and neuromuscular training feedback techniques to prevent ACL injury in female athletes. Strength and Conditioning Journal. 2011; 33(3):21-35. [DOI:10.1519/ SSC.0b013e318213afa8] [PMID] [PMCID]

[5] Myer GD, Ford KR, Hewett TE. Rationale and clinical techniques for anterior cruciate ligament injury prevention among female athletes. Journal of Athletic Training. 2004; 39(4):352-64. [PMCID]

[6] Ford KR, Myer GD, Hewett TE. Increased trunk motion in female athletes compared to males during single leg landing: 821June 1 8: 45 AM-9: 00 AM. Medicine \& Science in Sports \& Exercise. 2007; 39(5):S70. [DOI:10.1249/01. mss.0000273180.18215.3d]

[7] Hewett TE, Zazulak BT, Myer GD, Ford KR. A review of electromyographic activation levels, timing differences, and increased anterior cruciate ligament injury incidence in female athletes. British Journal of Sports Medicine. 2005; 39(6):34750. [DOI:10.1136/bjsm.2005.018572] [PMID] [PMCID]

[8] Hewett TE, Ford KR, Hoogenboom BJ, Myer GD. Understanding and preventing acl injuries: current biomechanical and epidemiologic considerations-update 2010. North American journal of Sports Physical Therapy: NAJSPT. 2010; 5(4):234-51. [PMCID]

[9] Cholewicki J, Silfies SP, Shah RA, Greene HS, Reeves NP, Alvi K, et al. Delayed trunk muscle reflex responses increase the risk of low back injuries. Spine. 2005; 30(23):2614-20. [DOI:10.1097/01.brs.0000188273.27463.bc] [PMID]

[10] Mills JD, Taunton JE, Mills WA. The effect of a 10-week training regimen on lumbo-pelvic stability and athletic performance in female athletes: A randomized-controlled trial. Physical Therapy in Sport. 2005; 6(2):60-6. [DOI:10.1016/j. ptsp.2005.02.006]

[11] Chomiak J, Junge A, Peterson L, Dvorak J. Severe injuries in football players. The American Journal of Sports Medicine.
2000; 28(suppl 5):S58-S68. [DOI:10.1177/28.suppl_5.s-58] [PMID]

[12] Ghaffarinejad F, Taghizadeh S, Mohammadi F. Effect of static stretching of muscles surrounding the knee on knee joint position sense. British Journal of Sports Medicine. 2007; 41(10):684-7. [DOI:10.1136/bjsm.2006.032425] [PMID] [PMCID]

[13] Loucks AB. Energy balance and body composition in sports and exercise. Journal of Sports Sciences. 2004; 22(1):1-14. [DO I:10.1080/0264041031000140518] [PMID]

[14] Sedaghati P, Saki F, Sarlak P. The impact of specific core stability training on the sports performance of teenage competitive swimmers. journal of Rafsanjan University of Medical Sciences. 2018; 17(4):305-18. http://journal.rums.ac.ir/ article-1-3987-en.html

[15] Sandrey MA, Mitzel JG. Improvement in dynamic balance and core endurance after a 6-week core-stability-training program in high school track and field athletes. Journal of Sport Rehabilitation. 2013; 22(4):264-71. [DOI:10.1123/ jsr.22.4.264] [PMID]

[16] Imai A, Kaneoka K, Okubo Y, Shiraki H. Effects of two types of trunk exercises on balance and athletic performance in youth soccer players. International Journal of Sports Physical Therapy. 2014; 9(1):47-57. [PMCID]

[17] Nesser TW, Lee WL. The relationship between core strength and performance in division I female soccer players. Journal of Exercise Physiology Online. 2009; 12(2):21-8. https:/ / www.sid.ir/en/journal/ViewPaper.aspx?ID=221655

[18] Kim M, Kim M, Oh S, Yoon B. The effectiveness of hollowing and bracing strategies with lumbar stabilization exercise in older adult women with nonspecific low back pain: A quasi-experimental study on a community-based rehabilitation. Journal of Manipulative and Physiological Therapeutics. 2018; 41(1):1-9. [DOI:10.1016/j.jmpt.2017.06.012] [PMID]

[19] Hodges PW. Core stability exercise in chronic low back pain. Orthopedic Clinics. 2003; 34(2):245-54. [DOI:10.1016/ S0030-5898(03)00003-8]

[20] Myer GD, Ford KR, Khoury J, Succop P, Hewett TE. Development and validation of a clinic-based prediction tool to identify female athletes at high risk for anterior cruciate ligament injury. The American Journal of Sports Medicine. 2010; 38(10):2025-33. [DOI:10.1177/0363546510370933] [PMID] [PMCID]

[21] Herrington L, Myer GD, Munro A. Intra and inter-tester reliability of the tuck jump assessment. Physical Therapy in Sport. 2013; 14(3):152-5. [DOI:10.1016/j.ptsp.2012.05.005] [PMID]

[22] Hong Y, Li JX, Robinson PD. Balance control, flexibility, and cardiorespiratory fitness among older Tai Chi practitioners. British Journal of Sports Medicine. 2000; 34(1):29-34. [DOI:10.1136/bjsm.34.1.29] [PMID] [PMCID]

[23] Gribble PA, Hertel J. Considerations for normalizing measures of the Star Excursion Balance Test. Measurement in Physical Education and Exercise Science. 2003; 7(2):89-100. [DOI:10.1207/S15327841MPEE0702_3]

[24] McGill SM, Childs A, Liebenson C. Endurance times for low back stabilization exercises: clinical targets for testing and training from a normal database. Archives of Physical Medi- 
cine and Rehabilitation. 1999; 80(8):941-4. [DOI:10.1016/ S0003-9993(99)90087-4]

[25] Willson JD, Davis IS. Lower extremity strength and mechanics during jumping in women with patellofemoral pain. Journal of Sport Rehabilitation. 2009; 18(1):76-90. [DOI:10.1123/jsr.18.1.76] [PMID]

[26] Bazett-Jones DM, Cobb SC, Joshi MN, Cashin SE, Earl JE. Normalizing hip muscle strength: Establishing body-sizeindependent measurements. Archives of Physical Medicine and Rehabilitation. 2011; 92(1):76-82. [DOI:10.1016/j. apmr.2010.08.020] [PMID]

[27] Razavi SS, Norasteh AA, Banparvari M. [The Relationship of Core Strength to Static and Dynamic Balance in Snowboard Skiing Male Athletes (Persian)]. Journal of Research in Rehabilitation Sciences. 2014; 10(3):432-43. https:/ / www. sid.ir/en/Journal/ViewPaper.aspx?ID=423936

[28] Liang L-C, Wang Y-T, Lee AJy. The effects of core stability training on dynamic balance in healthy young students. 34 rd International Conference On Biomechanics In Sports, 2016 Juiy 18-22, Tsukuba, Japan. in ISBS-Conference Proceedings Archive; 2016:219-22. file:///C:/Users/h/ Downloads/7025-Article\%20Text-21793-1-10-20161103.pdf

[29] Kahle NL, Gribble PA. Core stability training in dynamic balance testing among young, healthy adults. Athletic Training and Sports Health Care. 2009; 1(2):65-73. [DOI: 10.3928/19425864-20090301-03] 